\title{
Distribution of eight species of large-seeded pines and their primary animal seed-dispersers in China: match or mismatch?
}

\author{
manyu zhang ${ }^{1}$, Changxiang $\mathrm{Su}^{1}$, and Changhu $\mathrm{Lu}^{1}$ \\ ${ }^{1}$ Nanjing Forestry University
}

August 14, 2020

\begin{abstract}
Aim: The current geographic distribution of plants and their dispersers are a result of coevolution, but the reciprocity effects on the distribution of large seed pine and primary seed dispersers required understanding of (a) the distribution range and distribution characteristics of each species, and (b) the overlapping of distribution areas of animals and plants to explore whether they match. Location: China Methods: To find the target species, we identified eight large-seeded pine species in China in terms of seed size and wing traits as well as four primary seed disperser species in terms of body size, diet and food storage behavior. To map the geographical distribution, we obtained species distribution information from books, literature and GBIF. We then analyzed the distribution relationship by overlapping the distribution areas and patterns comprehensively. Results: We identified eight species of large-seeded pines (Pinus fenzeliana, P. gerardiana, P. dabeshanensis, P. koraiensis, P. pumila, P. bungeana, P. armandii, and P. sibirica) and four species of primary seed dispersers (Nucifraga caryocatactes, Sciurus vulgaris, Tamias sibiricus, and Sciurotamias davidianus). Pines interlaced from the Northeast to the Southwest of China along the mountains with an average altitude of 1000-2000 m, while each species of seed disperser had a wide distribution range that overlapped completely or partially with that of four or more species of the large-seeded pines. For pines that lack sufficient research on seed dispersal, our research provides them with potential seed dispersers Main conclusions: The distribution pattern of large-seeded pines and the primary seed dispersers was matched, we believed that reciprocal relationship promotes this distribution pattern. Our study highlights the importance of incorporating the ecological consequences of geographical distribution into reciprocal interactions between species and biodiversity conservation.
\end{abstract}

\section{KEYWORDS}

Coevolution, Distribution pattern, Large-seeded pines, Pinusplants, Reciprocal interaction, Seed dispersers

\section{1 | Introduction}

Plant distribution can be affected by climate changes, where climate warming can cause plant distribution areas to move more to the north (King et al., 2018), while anthropogenic influences, such as plant invasions via transportation (Ansong \& Pickering, 2013; Banks et al., 2015), landscaping (Dodet \& Collet, 2012), pollution control (An et al., 2007; Chu et al., 2006; Mao et al., 2019), and seed dispersal progression in the form of different modes of dispersal (Camargo et al., 2016), migration capacity (Pedrosa et al., 2019; Sunyer et al., 2013), feeding, and food storage behavior of animals can also change plant distributions (Barrere et al., 2020; Wang et al., 2019).

Seed dispersal promotes the regeneration of plants and the expansion of distribution areas (Levin et al., 2003). In this process, the seeds are first removed from the crowns of the parent tree by the dispersal agent (wind or animals) (Rodriguez-Perez \& Traveset, 2010; Rother et al., 2016), and then the seed rain is formed after the seed interacts with the media, in which the pattern of seed rain would ultimately affect the spatial distribution of plants (Nathan \& Mullerlandau, 2000; Wehncke \& Reyes, 2019). Hence, the demographic process in a plant's life cycle can be critical (Vivian \& Panetta, 2005). The consequence of seed dispersal 
by animals would primarily be determined via the interactions between the disperser home ranges and the position of the seed-bearing plants.

Pinus plants are major components of the numerous montane ecosystems in Asia, North America, and Europe, and are widely distributed in the Northern Hemisphere (Keeley, 2012; Richardson, 1998). There are about 111 species of pines globally (Richardson, 1998), most of which have winged seeds that can spread effectively over long distances via the wind (Benkman, 1995; Cain et al., 2000). However, about 29 species of pines cannot complete effective wind dispersal because of their large and windless or functionally wingless seeds, hence, they are often dispersed by rodents or birds (Tomback \& Linhart, 1990).

China is a globally important distribution area of Pinus plants with at least 23 species and 10 varieties of Pinus. The eight pines species include the Chinese white pine ( $P$. armandii $)$, the Korean pine $(P$. koraiensis ), the Siberian dwarf pine ( $P$. pumila ), the Dabieshan white pine ( $P$. dabieshanensis $)$, the Hunan white pine ( $P$. fenzeliana), the Chilgoza pine ( $P$. gerardiana ), the Lacebark pine $(P$. bungeana), and the Siberian stone pine ( $P$. sibirica), which cannot be dispersed effectively by wind because of their windless or functionally wingless seeds that are over 90g (thousand-grain weight) (Benkman, 1995) (Table 1). Among these, there are two endangered pines, i.e. the Korean pine (VU) and the Dabieshan white pine (EN), which are endemic to China (Wang \& Xie, 2004). We predicted that the pine seeds would be dispersed by animals. However, in addition to the Korean pine and Chinese white pine, the study of seed dispersal in other pines lacks sufficient field research, despite being important for understanding the ecological processes of montane ecosystems and protecting endangered pines.

Previous studies have focused on the seed dispersal process accompanied by the interaction between animals and plants, foraging behaviors, and the ecological consequences of seed dispersal. For example, Benkman et al. (1995) studied the American pines and found that the Red crossbills (Loxia curvirostra) and the Lodgepole pine (Pinus contorta) were in coevolutionary races, where the red squirrels (Tamiasciurus hudsonicus ) were absent, and the tree squirrels (Tamiasciurus ) were considered seed predators, they were all beneficial for seedling regeneration of the Limber pine (P. flexilis ) (Benkman et al., 1995). Vander (2010) mainly studied rodents and pines in America, and found that the Pinus plants, including other large-seeded plants such as the Cary spp and thePrunus spp., manipulate the scatter-hoarding behavior of seed-dispersing animals by producing large nutritious seeds, increasing the physical defense and masting, which improved the efficiency of seed dispersal (Vander , 2010). In addition, Lu (2002) studied the endangered pines in China as their focal species and they found that scatter-hoarding animals, such as chipmunk (Tamias sibiricus ), Eurasian red squirrel (Sciurus vulgaris ), and Eurasian nutcrackers (Nucifraga caryocatactes ), increased the regeneration of the Korean pine $(P$. koraiensis $)$ in the natural forest.

Furthermore, plants and their mutualist seed dispersers are products of diffuse coevolutionary processes. The current geographic distribution of plants and their dispersers is a result of coevolution. However, studies on the distribution match between the large-seeded pines and their seed dispersers is still scarce. We predicted that there would be strong positive correlations or a distribution match between animal-dispersed pines and animal dispersers. Our objectives were to investigate the large-seeded pines in China, summarize their distribution data, and examine the distribution relationship between these pines and their primary seed dispersers from the perspective of sympatry. This included a review of the large-scale distribution of the large-seeded pines, the animals that disperse pine seeds, and the existing literature regarding the seed dispersal of these pines.

\section{2 | Methods}

\section{1 | Data collection}

Several search engines were used to identify publications with abstracts that contain the Latin or Chinese names of the pines as well as the words "seed" and "seed dispersers". These search engines included Web of Science, Biological Abstracts, China National Knowledge Internet, and Wildlife \& Ecology Studies Worldwide. We retained only articles, reviews, and theses published in English and Chinese. After searching, 23 Chinese articles and 20 English articles were selected in terms of their contained information regarding 
seed dispersal of the eight specified species of pines (Table 3). In each study, the seed dispersers of the large-seeded pines were recorded.

To the best of our knowledge, the detailed pines and animal ranges available were Flora of China (Zheng \& Fu, 1978) and Fauna Sinica (Luo, 2000; Zhang, 2007), which were published by Science Press and hosted by the Chinese Academy of Science. Although these data are considered a landmark for studies conducted on the ecology and conservation of pines, rodents, and birds, updating the databases is demanding, but neglecting added information can be detrimental to conservation efforts (Hughes, 2017). In addition, we also referred to Pinus dabeshanensis and its Origin (Peng \& Jiang, 1999), Tibet Vegetation (Chinese Academy of Sciences, 1988), Flora and Vegetation Geography of China (Chen, 2014) and Floristics of Seed Plants from China $(\mathrm{Wu}, 2011)$ as literary references for the distribution of pines, while A Checklist on the Classification and Distribution of the Birds of China (Third Edition) (Zheng, 2017), China's Mammal Diversity and Geographic Distribution (Jiang et al., 2015), and Study on Rodents in Typical Semi-desert and Desert Areas of China (Wu et al., 2008) were the literary references for the distribution of seed dispersers.

We also queried the distribution information of these species from Global Biodiversity Information Facility (GBIF, 2020) (https://www.gbif.org/) as a supplement (see "Data available"), we obtained the distribution information of eight species of pines with geographical coordinates in China, and screened the information one by one. The records that were wrongly classified due to the wrong name of species were eliminated, and the effective records of each species were retained. There were no records of $P$. geraedana, 3 of $P$. pimila, 74 of $P$. bungeana , 505 of $P$. armandii , 22 of $P$. koraiensis and 28 of $P$. fenzeliana (excluding 106 records of $P$. kwangtungens, which were classified as Latin name errors). The species information on GBIF were obtained from the contributions of biologists and field researchers through time, but for species with poor habitat conditions, there would be a lack of information, while the habitat that is accessible to humans would have widely studied species. However, the distribution data could be inaccurate with differences between the GBIF data and the Chinese monograph. Hence, we chose to follow the data provided in Flora of China, Fauna Sinica, and local plant and animal record books, as mentioned previously.

\subsection{Distribution maps and analyses}

In this study, we produced up-to-date distribution maps of the eight species of the large-seeded pine. This included the following species: the Chinese white pine ( $P$. armandii ), the Korean pine ( $P$. koraiensis ), the Siberian dwarf pine ( $P$. pumila), the Dabieshan white pine ( $P$. dabieshanensis $)$, the Hunan white pine $(P$. fenzeliana $)$, the Chilgoza pine ( $P$. gerardiana ), the Lacebark pine $(P$. bungeana), and the Siberian stone pine ( $P$. sibirica) (Fig. 1). We also included the recorded seed dispersers, i.e. the chipmunk (Tamias sibiricus), the Eurasian red squirrel (Sciurus vulgaris), the Eurasian nutcrackers (Nucifraga caryocatactes ), and David's rock squirrels (Sciurotamias davidianus ). We also excluded the habitats of cities, lakes, rivers, and deserts, which are not suitable for these plants to live based on the known distribution areas. It was assumed that these plants could be distributed in other areas of the region. In addition, apart from the animals specially designated as having a discrete distribution in the literature, it was assumed that animals were present in a certain area. Compared to the habitats of animals, if there was no significant difference in the geographical environment of adjacent areas, we assumed the animal's distribution in those areas. ArcGIS 10.2 (Esri, USA) was used to analyze and visualize the results based on the 1:3,000,000 scale of the Chinese administrative geography vector map. Adobe Photoshop Pro CC 2018 (Adobe Inc., USA) was used to calculate the proportion of overlapping areas of both pines and animals (Zhong et al., 2015).

\section{3 | Results}

\section{1 | Geographical distribution of the large-seeded pines in China}

Generally speaking, the distribution of large-seeded pines is interlaced from Northeast to Southwest China. Among them, P. fenzeliana ,P. gerardiana, and P. dabeshanensis are distributed in dots (Fig. 1, Table 2).

$P$. fenzeliana is a unique species in China with a punctate distribution that is mainly found in the montane slope of Guangdong, Guangxi, and Hainan at an altitude of 1000-1600 m. P. gerardianais mainly found in 
the subalpine and xeric areas of Zada in Western Tibet at an altitude of approximately $2700 \mathrm{~m}$ as well as a small area in the northwest of the Himalayas. Because the distribution area of $P$. gerardiana in Tibet is narrow and located in the plateau, the research environment is difficult to sustain, hence, there is still no report on $P$. gerardiana seeds. $P$. dabeshanensis is a rare species that is endemic to China and is mainly distributed on the montane slopes of the Dabie Mountains in Southwestern Anhui and Eastern Hubei at an altitude of 900-1400 m. P. dabeshanensis is a rare and endangered species, where its pollen maturity occurs during the rainy season with a low success rate of pollination resulting in low seed yield. P. koraiensis is only distributed within the brown forest land zone with an elevation of $150-1800 \mathrm{~m}$ in the Changbai and Jilin Mountains as well as south of the Xiaoxing'an Mountains in Northeast China, where it is one of the primary forest species. In its natural distribution area, it is often found in a mixed broadleaf-conifer forest or a mixed coniferous forest. P. pumilais distributed within the arctic treeline and subalpine in the Daxing'an and Changbai Mountains in Northeast China at an altitude of 1200-1800 m.P. bungeana is an endemic species to China. It is mainly distributed within the steep south-facing mountain slopes at an altitude of 500-1800 m of Shanxi, Western Henan, Southern Gansu, Northern Sichuan, and Western Hubei. P. bungeana was clustered within the primary population and is the dominant species in the community.P. armandii is mainly distributed on the montane and limestone slopess of Southern Shanxi, Southwestern Henan, Shanxi, Southern Gansu, Sichuan, Western Hubei, Central and Northwestern Guizhou, Yunnan, and Tibet at an altitude of 1000-3300 m. Compared to the other Pinusspecies, P. armandii is the most widely distributed and covers the south of the Taihang Mountains. P. sibirica is distributed in the mountains and river valleys of the Kanas River in the upper reaches of Bulzin in the northern part of the Altai Mountains, Xinjiang. The climate of this basin is wet and cold throughout the year. In the ashing land zone of the mountainous grassland at an altitude of 1600-2350 m,P. sibirica often mixes with Larix sibirica to form a mixed forest that is mainly composed of $P$. sibirica .

\subsection{Seed dispersers of the large-seeded pines}

We screened the seed dispersers of $P$. dabeshanensis, P. koraiensis, P. pumila, and P. armandii, with regards to $P$. fenzeliana, $P$. gerardiana, $P$. bungeana, and $P$. sibirica. However, information regarding seed dispersal was not available (Table 3). The seed dispersers of $P$. dabeshanensisinclude Sciurotamias davidianus and Apodemus sylvaticus, which are small forest rodents, while the primary seed dispersers of $P$. koraiensis are Tamias sibiricus, Sciurus vulgaris, Sitta europaea, and Nucifraga caryocatactes, which are medium-sized birds and large rodents. Moreover, the primary seed dispersers of P. pumila are Sciurus vulgaris and $N$. caryocatactes with similar geographical distribution as $P$. koraiensis, thus, similar seed dispersers. We found that the seed disperser species of $P$. armandii were the most common, in which the only report showed that the $N$. caryocatactes were the primary seed disperser of $P$. sibirica . Combined with the body size, habitat, scatter-hoarding behavior, and diet (Jiang et al., 2015; MacKinnon \& Phillipps, 2000; Zhang, 2007), we identified four primary seed dispersers of the large-seeded pines in China, which consisted of $N$. caryocatactes, S. vulgaris, $S$. davidianus, and T. sibiricus (see S1 for details).

\section{3 | Primary seed dispersers}

The distribution of four primary seed dispersers and their overlap ratio with different pine distribution areas are shown in Fig. 2 and table 4, respectively.

$N$. caryocatactes is a typical coniferous forest bird that is mainly distributed across Northeast China (Fig. 2a). The distribution areas of $N$. caryocatactes cover $84.56 \%$ of $P$. armandii'sdistribution area. Additionally, it overlaps with all the distribution areas of the other pine trees, including P. koraiensis, P. pumila, and $P$. sibirica. Among the other pines of undetermined seed dispersal trends by $N$. caryocatactes, part of the distribution area of $P$. dabeshanensis and $P$. fenzeliana is are in the active area of $N$. caryocatactes, where the distribution areas of $P$. gerardiana and $P$. bungeanaare completely within the range of $N$. caryocatacte . This bird is very likely to eat the seeds of these pines, which indicates its potential role as their seed disperser.

S. vulgaris is mainly distributed across Northeastern to North China and is also present in some mountain 
forests in Northwestern China (Fig. 2b). At present, S. vulgaris have been reported to disperse the seeds of $P$. koraiensis and $P$. armandii. The natural geographical distribution of these two pines are all within the activity range of $S$. vulgaris . In addition, the distribution areas of $S$. vulgaris coincided with the geographical distribution area of $P$. sibirica and north of that as well as $7.20 \%$ of the distribution area of $P$. armandii, which also overlaps with $11.51 \%$ of the distribution area of $P$. bungeana. Therefore, S. vulgaris is likely to feed on the seeds of $P$. sibirica, $P$. armandii, and P. bungeana and disperses their seeds.

S. davidianus is mainly found in North China to Southwest China and East China to Midwest China (Fig. 2c). This covers all the geographical distribution areas of $P$. dabeshanensis, $P$. bungeana, $75.71 \%$ of $P$. armandii, and $6.16 \%$ of $P$. koraiensis . P. armandii and $P$. koraiensis have related reports in terms of seed dispersal by $S$. davidianus, where $91.61 \%$ of the geographical distribution areas of $P$. bungeana,$P$. dabeshanensis, and $P$. fenzeliana, with punctate distribution, overlap with that of $S$. davidianus, hence, $S$. davidianus is likely to feed on the seeds of the aforementioned pines and disperse their seeds through storage behavior.

T. sibiricus are mainly distributed in the northeast to the midwest of China (Fig. 2d). At present, there have been reports regarding the effect of $T$. sibiricus on the seed dispersal of $P$. koraiensis and $P$. armandii, where its geographic distribution covers $94.19 \%$ of the area of $P$. koraiensis and $57.21 \%$ of $P$. armandii's area. In addition, $49.58 \%$ of the geographical distribution areas of $P$. bungeana, part of $P$. fenzeliana, the total area of both $P$. pumila and P. sibirica coincided with that of $T$. sibiricus, in which it is likely to practice foraging and store behavior on the pine seeds, which would affect their seed dispersal.

Generally speaking, the distribution of the primary seed dispersers and the eight large-seeded pines showed a high degree of consistency, where central spreading of the Pinus plants was observed. The natural distribution areas of $P$. dabeshanensis, $P$. koraiensis ,P. armandii, and $P$. sibirica were all within the range of their main seed dispersers. For pines of undetermined seed dispersal trends, there were potential seed dispersers in some or all of their distribution areas. For each seed disperser species, its distribution range was wide with complete or partial overlaps with four or more species of the large-seeded pines. In addition to $P$. gerardiana, which is distributed at the highest altitude of $2700 \mathrm{~m}$, there were three or more seed dispersers in the distribution area of the other seven pine species, but two of them were only a small population with a spotty pattern of distribution.

\section{4 | Discussion}

To the best of our knowledge, this is the first attempt to overlap the geographical distribution of all largeseeded pines and their primary seed dispersers to explore the distribution relationship of these two different trophic groups. The geological factors regarding the formation of the pine trees distribution pattern in China and the effect of reciprocal interaction on the distribution of the large-seeded pines, seed dispersers, and the new reciprocal combinations was investigated.

We found that the distribution of large-seeded pines in China was interlaced from the northeast to the southwest as dots, which consisted of P. fenzeliana, P. gerardiana, and P. dabeshanensis . The Pinus plant origins include Western Europe and Eastern North America, where the early Pinus spread from Europe to East Asia through the ancient Mediterranean coast. North of the ancient Mediterranean region, the plants would spread freely and ultimately formed a distribution pattern that is found in China (Tao, 2012). The eight species of the large-seeded pines make one-third of China's pines that are mainly distributed along the mountainous areas at altitudes of $1000-2000 \mathrm{~m}$. They display adaptability to alpine and barren habitats, which is consistent with previous findings (Richardson, 1998; Tomback \& Linhart, 1990).

Large seeds are considered to be a tradeoff in terms of promoting seed germination and seedling growth as well as seed dispersal by animals. The evolutionary process of bird dependency caused pines to grow at high elevation or in barren environments that are sympatric with one or more corvids with seed-storing behavior and increased seed size (Tomback \& Linhart, 1990). In addition, rodents with scatter-hoarding behavior brought new changes to such interactions, even though their home range is much smaller than those of a nutcracker (Vander, W., Stephen B. \& Beck, 2011; Vander, W., Stephen B. et al., 2006). 
In this study, we found that the distribution of nutcrackers runs through the distribution areas of only seven species of the large-seeded pines, while the distribution area of the rodent was smaller and their distribution with the pines had a large overlap. This difference between birds and rodents could be related to movement and ecological traits.S. vulgaris showed a preference for pine seeds by storing large amounts of seeds in the mature season to cope with food shortages in the winter and early spring. Thus, they can only be distributed in areas with larger pine seeds (Siepielski \& Benkman, 2008; Yu et al., 2014). As T. sibiricus are omnivores, they eat young buds, leaves, and flowers, and they hibernate during the season when pine seeds are scarce, hence, they can be distributed more widely. These rodents, either scatter-hoarding or larder-hoarding, retrieve food by olfaction. However, when seeds are buried too deep or for too long, then the seeds are more difficult to find, thus improving the survival rate of seeds (Fletcher et al., 2010; Zhang \& Zhang, 2007). Moreover, $N$. caryocatactes is a typical coniferous forest bird that disperses and stores a large number of seeds for winter in the seed maturity season and has a strong spatial memory for finding the seeds (Balda, 1980).

Furthermore, our results were based on the large overlap of the spatial scale distribution, which could add uncertainty to widely distributed species, such as $P$. armandii, but not evolutionary clues regarding the pines due to the lack of seed dispersal research, which we believe is crucial. For the four primary seed disperser of pines, S. vulgariss is mainly distributed across northern China, while $T$. sibiricus and $N$. caryocatactes are distributed in the same range as all the eight pine species. S. davidianus cover the mountains of central China, which partially or a completely overlaps with the range of $P$. fenzeliana $P$. dabeshanensis, $P$. bungeana, and $P$. armandii. This highlighted the central spreading pattern of Pinus plants in central China. The results of the overlapping distribution confirmed that the potential interaction not previously discovered between large-seeded pines and animals, where $N$. caryocatactes, $S$. davidianus, and $T$. sibiricus were found in the distribution area of $P$. fenzeliana and $N$. caryocatactes, while $P$. gerardiana, $N$. caryocatactes,$S$. vulgaris , T. sibiricus, and $S$. davidianus were found in the distribution area of $P$. bungeana, hence, these animals may be potential seed dispersers of these pines. In addition, we found T. sibiricus in the distribution area of $P$. pumila ,S. vulgaris, and T. sibiricus, which was in the distribution area of $P$. sibirica, while $N$. caryocatacteswas in the distribution area of $P$. dabeshanensis, where these animals were not identified in previous studies. Similarly, they may have certain foraging and dispersal effects on the pine trees. We identified new combinations of pines and seed dispersers that were previously described but not found as well as combinations that have not been studied. Sympatry studies are valuable to identify the relationships between animals and plants, where Piazzon et al. predicted that the interspecific variation in seed rain was based on plant distribution and lizard movement patterns (Piazzon et al., 2012), while Barrere et al. studied feeding behaviors of sympatric red and roe deer relative to the oak mast seedling (Barrere et al., 2020).

More detailed studies should be performed regarding the process and mechanism of the seed dispersal of large-seeded pines. The effects of animal dispersal on Pinus species are often changed by the seed disperser species, their foraging behavior, habitat type, seed-bearing year (old or young), and other factors (Peters et al. , 2017). In view of the reported large-seeded pines, long-term, large-scale, and multi-factorial observations and tracking should be conducted to understand the dynamic changes in the species, abundance, behavior, and population dynamics of the seed disperser community in different habitats. The large-seeded pines that have not yet been studied should be investigated relative to the ones in China. Based on these data, an evolutionary model of the large-seeded pine was established based on the reciprocal relationships found between animals and plants.

\section{REFERENCES}

An, S., Gu, B., Zhou, C., Wang, Z., Deng, Z., Zhi, Y., . . . Liu, Y. (2007). Spartina invasion in China: implications for invasive species management and future research. Weed Research, 47 (3), 183-191.

Ansong, M., \& Pickering, C. (2013). Are Weeds Hitchhiking a Ride on Your Car? A Systematic Review of Seed Dispersal on Cars. Plos One, 8 (11), e80275. https://doi.org/ARTN e80275

10.1371/journal.pone.0080275 
Balda, R. P. (1980). Recovery of cached seeds by a captive Nucifraga caryocatactes. Ethology, 52 (4), 331-346. https://doi.org/10.1111/j.1439-0310.1980.tb00721.x

Banks, N. C., Paini, D. R., Bayliss, K. L., \& Hodda, M. (2015). The role of global trade and transport network topology in the human-mediated dispersal of alien species. Ecology Letters, 18 (2), 188-199. https://doi.org/10.1111/ele.12397

Barrere, J., Boulanger, V., Collet, C., Walker, E., Siat, V., Henry, L., \& Saïd, S. (2020). How does oak mast seeding affect the feeding behavior of sympatric red and roe deer? Basic and Applied Ecology . https://doi.org/https://doi.org/10.1016/j.baae.2020.04.006

Benkman, C. W. (1995). The impact of tree squirrels (Tamiasciurus) on limber pine seed dispersal adaptations. Evolution, 49 (4), 585-592.

Benkman, C. W. (1995). Wind dispersal capacity of pine seeds and the evolution of different seed dispersal modes in pines. Oikos, 73 (2), 221-224. https://doi.org/10.2307/3545911

Bureau, S. F. (2001). Seeds of Woody Plants in China : Beijing:China Forestry Publishing House.

Cain, M. L., Milligan, B. G., \& Strand, A. E. (2000). Long-distance seed dispersal in plant populations. American Journal of Botany, 87 (9), 1217-1227.

Camargo, P. H. S. A., Martins, M. M., Feitosa, R. M., \& Christianini, A. V. (2016). Bird and ant synergy increase the seed dispersal effectiveness of an ornithochoric shrub. Oecologia, 181 (2), 507-518. https://doi.org/10.1007/s00442-016-3571-z

Chen, F., \& Chen, J. (2011). Effects of Pinus armandii seed size on rodents caching behavior and it's spatiotemporal variations.Zoological Research, 32 (4), 435-441. https://doi.org/10.3724/SP.J.1141.2011.04435

Chen, L. Z. (2014). Flora and vegetation geography of China . Beijing: Science Press.

Chu, J., Ding, Y., \& Zhuang, Q. (2006). Invasion and control of water hyacinth (Eichhornia crassipes) in China. Journal of Zhejiang University-science B, 7 (8), 623-626.

Dodet, M., \& Collet, C. (2012). When should exotic forest plantation tree species be considered as an invasive threat and how should we treat them? Biological Invasions, 14 (9), 1765-1778. https://doi.org/10.1007/s10530-012-0202-4

Duan, X. P., \& Chen, W. J. (1992). A preliminary study on seed dormancy physiology of Pinus kwangtungensis. Hunan Forestry Science 83 Technology (03), 25-30.

Fletcher, Q. E., Boutin, S., Lane, J. E., Lamontagne, J. M., Mcadam, A. G., Krebs, C. J., \& Humphries, M. M. (2010). The functional response of a hoarding seed predator to mast seeding. Ecology, 91 (9), 2673-2683.https://doi.org/10.1890/09-1816.1

GBIF: The Global Biodiversity Information Facility (2020) What is GBIF?. Available from https://www.gbif.org/what-is-gbif.

Ghildiyal, S. K., Sharma, C. M., \& Gairola, S. (2009). Environmental variation in seed and seedling characteristics of Pinus roxburghii Sarg. From Uttarakhand, India. Applied Ecology and Environmental Research, 7 (2), 121-129. https://doi.org/10.15666/aeer/0702_121129

Han, C., Xu, J. M., \& Tong, Q. (2014). Study on the selection of provenance / family of Pinus australis introduction at Seedling Stage.Chinese Agricultural Science Bulletin, 30 (19), 7-12.

Hughes, A. C. (2017). Mapping priorities for conservation in Southeast Asia. Biological Conservation, 209 , 395-405.

Hutchins, H. E., Hutchins, S. A., \& Liu, B. (1996). The role of birds and mammals in Korean pine (Pinus koraiensis) regeneration dynamics. Oecologia, 107 (1), 120-130. https://doi.org/10.1007/BF00582242 
Jiang, C. (2015). Survey Report on Pinus dabeshanensis Resources in Yuexi County. Anhui Forestry Science and Technology, 41 (06), 69-70.

Jiang, M. X. (1982). A preliminary study on the distribution and growth of yanpine in Daxingan mountains. Scientia Silvae Sinicae, 2 , 203-205.

Jiang, Z. G., Ma, Y., \& Wu, Y. (2015). China's mammal diversity and geographic distribution . Beijing: Science Press.

Kajimoto, T. (2002). Factors affecting seedling recruitment and survivorship of the Japanese subalpine stone pine, Pinus pumila, after seed dispersal by nutcrackers. Ecological Research, 17 (4), 481-491. https://doi.org/10.1046/j.1440-1703.2002.00505.x

Kajimoto, T., Onodera, H., Ikeda, S., Daimaru, H., \& Seki, T. (1998). Seedling establishment of subalpine stone pine (Pinus pumila) by Nutcracker (Nucifraga) seed dispersal on Mt. Yumori, Northern Japan.Arctic and alpine research, 30 (4), 408-417.

Keeley, J. E. (2012). Ecology and evolution of pine life histories.Annals of Forest Science, 69 (4), 445-453. https://doi.org/10.1007/s13595-012-0201-8

King, M., Altdorff, D., Li, P., Galagedara, L., Holden, J., \& Unc, A. (2018). Northward shift of the agricultural climate zone under 21st-century global climate change. Scientific Reports, 8 (1), 7904. https://doi.org/10.1038/s41598-018-26321-8

Levin, S. A., Muller-Landau, H. C., Nathan, R., \& Chave, J. (2003). The ecology and evolution of seed dispersal: A theoretical perspective.Annual Review of Ecology Evolution and Systematics, 34, 575-604. https://doi.org/10.1146/annurev.ecolsys.34.011802.132428

Lu, C. H. (2002). Hoarding behavior of eurasian nutcracker (Nucifraga caryocatact) and its role in seed dispersal of Korean pine (Pinus koraiensis). Acta Zoologica Sinica, 48 (03), 317-321. https://doi.org/10.3969/j.issn.1674-5507.2002.03.004

Lu, C. H. (2006). Roles of animals in seed dispersal of Pinus: A review. Chinese Journal of Ecology, 25 (5), 557-562.

Luo, Z. (2000). Fauna Sinica: Rodentia. In C. a. o. science (Ed.),Fauna Sinica (Vol. 6). Beijing: Science press.

MacKinnon, J., \& Phillipps, K. (2000). A field guide to the birds of China . Changsha: Hunan Education Press.

Mao, D., Liu, M., Wang, Z., Li, L., Man, W., Jia, M., \& Zhang, Y. (2019). Rapid Invasion of Spartina Alterniflora in the Coastal Zone of Mainland China: Spatiotemporal Patterns and Human Prevention.Sensors, 19 (10), 2308.

Miyaki, M. (1987). Seed dispersal of the Korean pine, Pinus koraiensis, by the red squirrel, Sciurus vulgaris. Ecological Research, 2 (2), 147-157. https://doi.org/10.1007/BF02346923

Mokotjomela, T. M., Downs, C. T., Esler, K., \& Knight, J. (2016). Seed dispersal effectiveness: A comparison of four bird species feeding on seeds of invasive Acacia cyclops in South Africa. South African Journal of Botany, 105 , 259-263. https://doi.org/10.1016/j.sajb.2016.04.005

Nathan, R., \& Mullerlandau, H. C. (2000). Spatial patterns of seed dispersal, their determinants and consequences for recruitment. Trends in Ecology $\mathscr{G}$ Evolution, 15 (7), 278-285.

Pedrosa, F., Berce, W., Levi, T., Pires, M., \& Galetti, M. (2019). Seed dispersal effectiveness by a largebodied invasive species in defaunated landscapes. Biotropica . https://doi.org/10.1111/btp.12706

Peng, Z. H., \& Jiang, Z. H. (1999). Pinus dabeshanensis and its origin . Beijing: China Forestry Publishing House. 
Piazzon, M., Larrinaga, A. R., Rodriguez-Perez, J., Latorre, L., Navarro, L., \& Santamaria, L. (2012). Seed dispersal by lizards on a continental-shelf island: predicting interspecific variation in seed rain based on plant distribution and lizard movement patterns.Journal of Biogeography, 39 (11), 1984-1995. https://doi.org/10.1111/j.1365-2699.2012.02718.x

Rey, P. J., \& Alcantara, J. M. (2014). Effects of habitat alteration on the effectiveness of plant-avian seed dispersal mutualisms: Consequences for plant regeneration. Perspectives in Plant Ecology Evolution and Systematics, 16 (1), 21-31. https://doi.org/10.1016/j.ppees.2013.11.001

Richardson, D. M. (1998). Ecology and Biogeography of Pinus . Cambridge: Cambridge University Press.

Riser, J. P. (2002). Book review: Ecology and Biogeography of Pinus.Systematic Botany, 27 (3), 636-637.

Rodriguez-Perez, J., \& Traveset, A. (2010). Seed dispersal effectiveness in a plant-lizard interaction and its consequences for plant regeneration after disperser loss. Plant Ecology, 207 (2), 269-280. https://doi.org/10.1007/s11258-009-9671-7

Rother, D. C., Pizo, M. A., \& Jordano, P. (2016). Variation in seed dispersal effectiveness: the redundancy of consequences in diversified tropical frugivore assemblages. Oikos, 125 (3), 336-342. https://doi.org/10.1111/oik.02629

sciences, C. a. o. (1988). Tibet vegetation . Beijing: Science Press.

Siepielski, A. M., \& Benkman, C. W. (2008). A seed predator drives the evolution of a seed dispersal mutualism. Proceedings Of the Royal Society B-Biological Sciences, 275 (1645), 1917-1925. https://doi.org/10.1098/rspb.2008.0451

Singh, R. V., Khanduri, D. C., \& Lal, K. (1973). Chilgoza Pine (Pinus gerardiana) Regeneration in Himachal Pradesh. The Indian Forester, 99 (3), 126-133.

Su, C. X., Zhong, Z. F., \& Lu, C. H. (2018). Role of animals in the natural population regeneration of Pinus dabeshanensis. Acta Ecologica Sinica, 38 (17), 6194-6203. https://doi.org/10.5846/stxb201710281933

Sunyer, P., Munoz, A., Bonal, R., \& Espelta, J. M. (2013). The ecology of seed dispersal by small rodents: a role for predator and conspecific scents. Functional Ecology, 27 (6), 1313-1321. https://doi.org/10.1111/1365-2435.12143

Tao, C. (2012). A study on the endangered mechanism of endangered plants in sect strobus in China. (Master), Beijing Forestry University, Beijing.

Tomback, D. F., \& Linhart, Y. B. (1990). The evolution of bird-dispersed pines. Evolutionary Ecology, 4 (3), 185-219. https://doi.org/10.1007/bf02214330

Vander, W., Stephen B., \& Beck, M. J. (2011). A Comparison of Frugivory and Scatter-Hoarding SeedDispersal Syndromes. The Botanical Review, 78 (1), 10-31. https://doi.org/10.1007/s12229-011-9093-9

Vander, W., Stephen B., Briggs, J. S., Jenkins, S. H., Kuhn, K. M., Thayer, T. C., \& Beck, M. J. (2006). Do food-hoarding animals have a cache recovery advantage? Determining recovery of stored food.Animal Behaviour, 72 (1), 189-197. https://doi.org/10.1016/j.anbehav.2006.01.004

Vander, W. S. B. (2010). How plants manipulate the scatter-hoarding behaviour of seeddispersing animals. Philosophical Transactions of the Royal Society B, 365 (1542), 989-997. https://doi.org/10.1098/rstb.2009.0205

Vivian, S., G., \& Panetta, F. D. (2005). Seedling recruitment, seed persistence and aspects of dispersal ecology of the invasive moth vine, Araujia sericifera (Asclepiadaceae). Australian Journal of Botany, 53 (3), 225-230. https://doi.org/10.1071/Bt04118

Wang, B., \& Ives, A. R. (2017). Tree-to-tree variation in seed size and its consequences for seed dispersal versus predation by rodents.Oecologia, 183 (3), 751-762. https://doi.org/10.1007/s00442-016-3793-0 
Wang, B., Wang, G., \& Chen, J. (2012). Scatter-hoarding rodents use different foraging strategies for seeds from different plant species.Plant Ecology, 213 (8), 1329-1336. https://doi.org/10.1007/s11258-012-0091-8

Wang, S., \& Xie, Y. (2004). China species red list . Beijing: Higer education press.

Wang, Z. Y., Wang, B., Yi, X. F., Yan, C., Zhang, Z. B., \& Cao, L. (2019). Re-caching behaviour of rodents improves seed dispersal effectiveness: Evidence from seedling establishment. Forest Ecology and Management, 444 , 207-213. https://doi.org/10.1016/j.foreco.2019.04.044

Wehncke, E. V., \& Reyes, A., Josue. (2019). Seed Dispersal and Conservation. In Encyclopedia of Animal Behavior (pp. 283-290).

Wu, X. D., Fu, H. P., \& Yang, Z. L. (2008). Study on rodents in typical semi-desert and desert areas of China . Beijing: Science Press.

Wu, Z. Y. (2011). Floristics of seed plants from China . Beijing: Science Press.

Xiang, X. Y., Wu, G. L., \& Wang, Z. G. (2016). Comparison of seed characteristics of Pinus dabeshaneses in different seed stands. Journal of Anqing Normal University (Natural Science Edition), 22 (3), 110-112.

Yi, X. F., Xiao, Z. S., \& Zhang, Z. B. (2008). Seed dispersal of Korean pine Pinus koraiensis labeled by two different tags in a northern temperate forest, northeast China. Ecological Research, 23 (2), 379-384. https://doi.org/10.1007/s11284-007-0392-x

Yu, F., Wang, D. X., Yi, X. F., Shi, X. X., Huang, Y. K., Zhang, H. W., \& Zhang, X. P. (2014). Does animal-mediated seed dispersal facilitate the formation of Pinus armandii-Quercus aliena var. acuteserrata forests? Plos One, 9 (2), e89886. https://doi.org/10.1371/journal.pone.0089886

Zhang, H. M., \& Zhang, Z. B. (2007). Key factors affecting the capacity of David's rock squirrels (Sciurotamias davidianus) to discover scatter-hoarded seeds in enclosures. Biodiversity Science, 26 (4), 329-336.

Zhang, J. X., \& Yuan, Y. Z. (1988). A study on the biomass and production of Pinus fenzeliana forest in hainan. Acta phytoecologyica et geobotanica sinica (01), 65-71.

Zhang, Y. Y., \& Cai, H. Q. (1989). Geographical Distribution and Community Ecology of Pinus armandii. Hunan Forestry Science 83 Technology (04), 5-8.

Zhang, Z. X. (2007). Fauna Sinica: Passerifores (Chinese academy of sciences Ed.). Beijing: Science Press.

Zhao, G. Y. (1981). Investigation about Distribution of Pinus sibirica in Daxing'an Mountains and Northwest Limit of Pinus koraiensis in China. Journal of Northeast Forestry University (02), 31-40.

Zhao, Y., Zhang, X. Z., \& Wang, X. A. (1995). A study on geographical distribution law of Pinus bungeana natural forests in China. Acta Botanica Boreali-Occidentalia Sinica (02), 161-166.

Zheng, G. M. (2017). A Checklist on the Classification and Distribution of the Birds of China (Third Edition) . Beijing: Science Press.

Zheng, W. J., \& Fu, L. G. (1978). Flora of China: Gymnospermae(Chinese academy of sciences Ed. Vol. 7). Beijing: Science Press.

Zhong, J., Bai, X. R., \& Jiang, X. J. (2015). China Patent No. CN104457627A. 

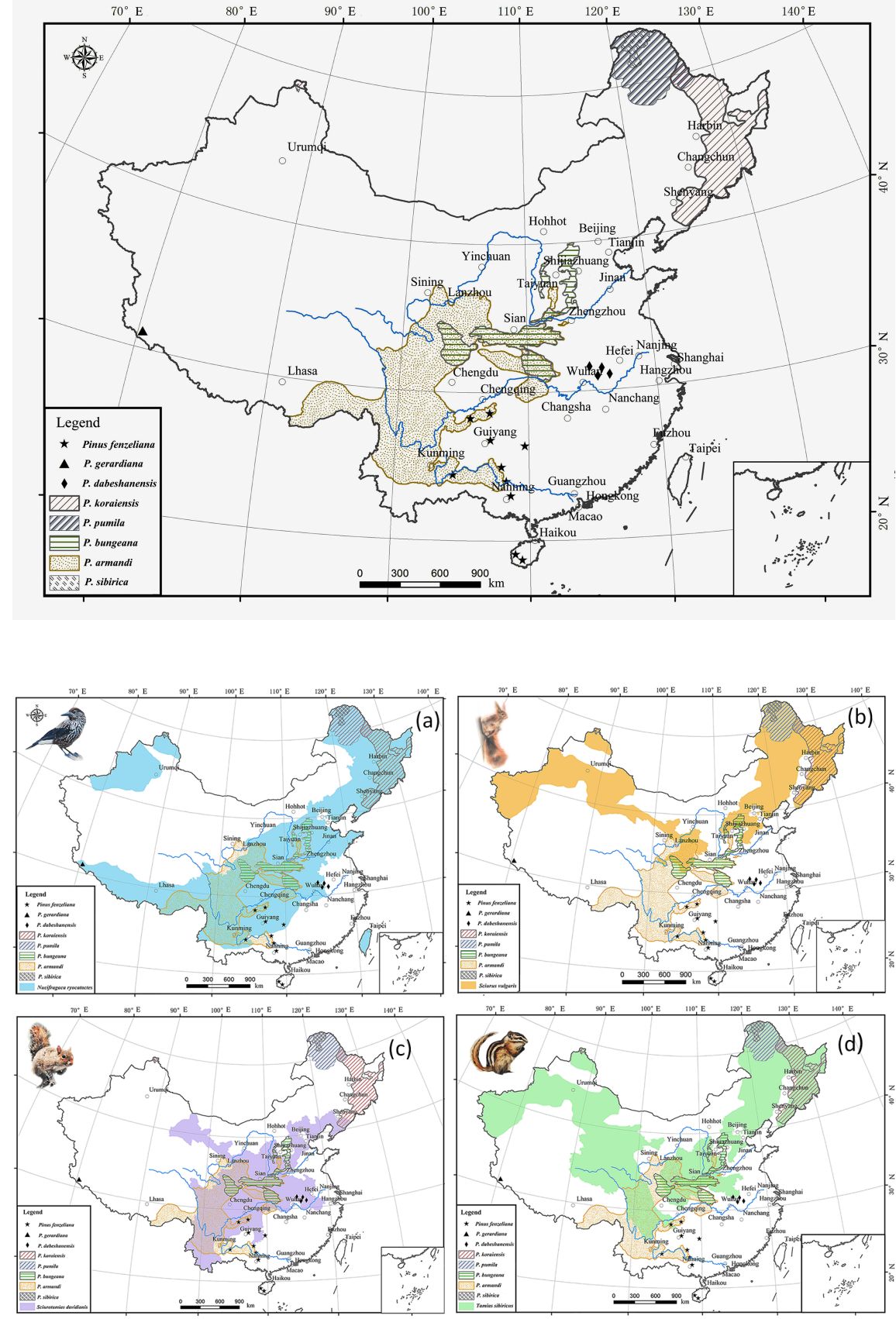